\title{
The prevalence, patterns of usage and people's attitude towards complementary and alternative medicine (CAM) among the Indian community in Chatsworth, South Africa
} Vimal Singh ${ }^{1}$, Deshandra M Raidoo ${ }^{1,2}$ and Catherine S Harries*1

\author{
Address: ${ }^{1}$ Department of Pharmacology, Nelson R Mandela School of Medicine, University of Natal, South Africa and ${ }^{2}$ Current address: School of \\ Medicine, Division of Health Sciences, University of South Dakota, USA \\ Email: Vimal Singh - vimal.singh@webmail.co.za; Deshandra M Raidoo - draidoo@usd.edu; Catherine S Harries* - harriesk@nu.ac.za \\ * Corresponding author
}

Published: 04 February 2004

BMC Complementary and Alternative Medicine 2004, 4:3
Received: 10 November 2003

Accepted: 04 February 2004

This article is available from: http://www.biomedcentral.com//472-6882/4/3

(C) 2004 Singh et al; licensee BioMed Central Ltd. This is an Open Access article: verbatim copying and redistribution of this article are permitted in all media for any purpose, provided this notice is preserved along with the article's original URL.

\begin{abstract}
Background: The purpose of this study was to determine, among the Indian community of Chatsworth, South Africa, the prevalence and utilisation patterns of complementary and alternative medicine (CAM), attitudes associated with CAM use and communication patterns of CAM users with their primary care doctors.
\end{abstract}

Methods: Face-to-face structured interviews were conducted in Chatsworth, a suburb of Durban in which South Africans of Indian origin predominantly reside. Participants were 200 randomly selected adult English-speaking Indian residents.

Results: The prevalence of CAM usage for period 2000/200I was 38.5\% ( $95 \%$ confidence interval $31.7 \%$ to $45.6 \%$ ). Spiritual healing and herbal/natural medicines, including vitamins were the most common types of CAM used, accounting for $42.8 \%$ and $48.1 \%$ respectively of overall CAM usage. People used CAM to treat conditions including diabetes mellitus, headaches, arthritis and joint pains, stress, skin disorders, backaches, hypertension and nasal disorders. Half of the CAM users used allopathic medicines concurrently. The cost of CAM utilization over this I-year period, incurred by $80.5 \%$ of users for the duration of therapy for their most troublesome condition was below R500 (approximately US\$50). Age, sex, marital status, religion, level of education and income were shown not to influence the use of CAM. Greater than half (5I.9\%) of CAM users did so either upon the advice of someone they knew, or after noticing a CAM advertisement in the local press. Seventy-nine percent of CAM users indicated that they had positive outcomes with their treatments. Fifty four percent of CAM users (excluding those using spiritual healing only) failed to inform their doctors that they used CAM. The main reason given by half of this group was that informing their doctors did not seem necessary.

Conclusion: The prevalence of CAM in Chatsworth is similar to findings in other parts of the world. Although CAM was used to treat many different ailments, this practice could not be attributed to any particular demographic profile. The majority of CAM users were satisfied with the effects of CAM. Findings support a need for greater integration of allopathic medicine and CAM, as well as improved communication between patients and caregivers regarding CAM usage. 


\section{Background}

There is documented evidence that the use of complementary and alternative medicine (CAM) among western society is high [1-3], and that its use is increasing worldwide [2,4-6]. A US survey in 1993 found that 34\% of Americans were using at least one type of alternative therapy [1]. A follow-up survey in 1998 reported that $40 \%$ of Americans used CAM for chronic conditions in the preceding year [5]. They made a staggering 629 million visits to CAM practitioners, far exceeding the 386 million visits made to primary care physicians during the same year. In European countries for which statistics are available, complementary therapies are used by $20-50 \%$ of the population [2]. An Australian survey in 1992/1993 found that 48.5\% of the population used at least one non-medically prescribed alternative therapeutic modality [3]. Barnes et al conducted a systematic literature search of the MEDLINE database from 1966 through to 1996, to investigate the growth of interest in CAM by the professional scientific community [6]. They concluded that interest in and awareness of complementary medicine among orthodox health care professionals had increased during this period, and that the number of studies on alternative medicine published in scientific journals was increasing. Studies suggesting that church going, religious beliefs, and prayer can improve morbidity and mortality have received attention in medical journals and the general media [7]. Numerous articles, advertisements and supplements on CAM are appearing in the local and regional South African newspapers such as the Chatsworth Times, Rising Sun, Sunday Tribune and Post, as well as local magazines such as Durban's Metro Beat. These heighten public interest and lend authority to therapies or medicines that were previously labeled as merely having a "placebo effect".

Unconventional, alternative or unorthodox therapies are difficult to define because they encompass a broad spectrum of practices and beliefs. The term "alternative medicine" may suggest an opposition to allopathic medicine, but the word "alternative" simply means "other". The American National Institute of Health's Office of Alternative Medicine developed a more precise or scientific classification of CAM that differentiates seven categories listed in table 1[8]. The influence of cultural beliefs on the use of CAM is experienced in the Chinese and African traditions. In Chinese medicine the doctrine of "Five Elements" had a major influence on acupuncture and all aspects of society [9]. Traditional African healing is described as something "people have put their faith in for years" [10].

In an essay aimed at improving understanding and communication among physicians, patients and providers of CAM, American researchers Kaptchuk and Eisenberg suggest that the attraction of alternative therapies may be related to the power of the underlying philosophies they share, which involve nature, vitalism, "science" and spirituality [11]. Kapchuk and Eisenberg describe the effect of these principles: "Taken together, these principles expand behavioral options, identity, experience and meaning when illness threatens a person's intactness and sense of connection to the world."

Further reasons why patients are attracted to CAM have been suggested. Astin et al proposed that besides patients finding many alternative therapies more congruent with their philosophical orientation toward health, they also preferred practitioners who took the time to listen, understand and deal with their personal life as well as pathology [12]. As conventional medicine in the USA becomes increasingly expensive, depersonalised, and unable to adequately meet the needs of patients with chronic conditions, Husted et al found that many such patients were seeking health promotion strategies to effectively manage their symptoms [13]. CAM is common amongst people with chronic ailments such as rheumatologic conditions $[14,15]$, breast cancer [16,17], asthma [18], inflammatory bowel disease [19], headache $[1,20]$, back problems and chronic pain $[1,21,22]$, as well as degenerative conditions like multiple sclerosis [13].

Strong cultural beliefs, a high prevalence of chronic illnesses like diabetes mellitus, hypertension and coronary artery disease, as well as an increasing number of advertisements for CAM appearing in the local community newspapers were indicators that the Indian community in Chatsworth would use some form of CAM. The prevalence of such forms of healing within this community has not been previously reported. Hence, this study ascertains the prevalence of CAM usage and examines some of the factors and reasons governing the choice of this kind of healthcare within the Indian community, adding valuable information about a little-researched group in South Africa.

\section{Methods}

The study was approved by the Ethics Committee of the Nelson R. Mandela School of Medicine, University of Natal. The study population was the adult Indian population of Chatsworth, a suburb of Durban. A sample size of 200 respondents was used since this would allow for a $50 \%$ prevalence estimate with a $95 \%$ confidence interval ranging from $43-57 \%$. The population sample was obtained with the aid of the Ethekwini Municipality's property valuation roll. A household number was assigned to every physical address appearing in the valuation roll. A random sample of 200 was drawn from the household numbers. Each of these numbers was then matched to its physical address, which constituted the household that was selected for an interview. One volun- 
Table I: Categories of complementary and alternative medicine together with examples

\begin{tabular}{|c|c|}
\hline Category & Description / Examples \\
\hline Mind-Body Interventions & Biofeedback, relaxation techniques, meditation, hypnosis, imagery, yoga and t'ai chi. \\
\hline Biomagnetic Therapies & $\begin{array}{l}\text { Exposure to strongly ionizing electromagnetic radiation and nonionising electromagnetic fields; } \\
\text { transcutaneous electrical nerve stimulation. }\end{array}$ \\
\hline Alternative Systems of Medical Practice & Ayurveda, Chinese medicine and homeopathy \\
\hline Manual Healing Methods & Osteopathic and chiropractic manipulation; physical therapy and massage; therapeutic touch \\
\hline Pharmacological and Biologic Treatments & Chelation therapy and intravenous ozone therapy \\
\hline Herbal Medicine & Various botanical remedies \\
\hline Diet and nutrition & $\begin{array}{l}\text { Special dietary strategies to address prevention or cure. e.g. vitamin E to reduce the risk of clots; a } \\
\text { diet based on brown rice and vegetables used to treat cancer and other chronic illnesses; the } \\
\text { Gerson diet, which consists of raw vegetables as well as vegetable and fruit juices }\end{array}$ \\
\hline
\end{tabular}

teer per household was requested to answer the questionnaire. A volunteer was accepted if he/she was 18 years and older, understood English, and was an Indian resident of Chatsworth. Residents of flats and informal settlements were excluded for safety reasons. Households that refused to volunteer for an interview were replaced by the next house on the list.

For this interview-based study, we adapted questionnaires developed by Eisenberg et al [1] and MacLennan et al [3] and used these to conduct interviews from September 2001 to March 2002. The questionnaire was divided into two sections: demographics and health information. Demographic data included area of residency within the suburb, age, sex, marital status, level of education, religion, annual income of the respondent, alcohol consumption and cigarette smoking. In the health section, respondents were asked to list up to three of their most troublesome conditions and whether they had consulted a medical practitioner or used any form of CAM for these conditions during the previous 12 months. Respondents could choose from the following list of CAM practices: acupuncture, aromatherapy, African traditional healing, Ayurvedic medicine, colon therapy, commercial weight loss programmes, herbal/natural medicines and/or vitamins, chiropody, energy healing techniques, exercise and special diet not prescribed by a medical practitioner, homeopathy, hypnosis, massage therapy excluding physiotherapy, reflexology, spiritual healing and other (specify). Respondents were then asked to describe their perceptions of the efficacy of such treatments and provide an estimate of the costs incurred for CAM for the duration of therapy for their most troublesome condition. They were also asked to provide one or more reasons for choosing CAM as a therapeutic modality. Furthermore, the questionnaire ascertained whether they used CAM alone or in conjunction with medicines prescribed by their medical practitioner, and whether they had informed their medical practitioner of the CAM they were using. Finally, all respondents were asked which form of medical care they would prefer, i.e. modern medicine, CAM, or both, as well as reasons for making such choices.

The collected data was entered onto spreadsheets, using the Microsoft Excel ${ }^{\oplus}$ software programme, then imported to the Epi-info 2002 programme, where users and nonusers of CAM were compared. These groups were assessed for differences in demographic variables using the chisquared test. The conventional 0.05 level of statistical significance was used to determine whether there were differences between the groups, as reported in table 2 .

\section{Results \\ Demographics}

Of 210 homes visited, 10 households declined consent and two hundred patients were interviewed and completed face-to-face structured interviews. Additional file 1, a table of subject characteristics, shows that there were similar numbers of respondents from each of the subareas or units of Chatsworth (no units 4 and 8 exist in Chatsworth); equal sex distribution and a predominantly married sample with the majority of people in the 26-60 age group. More than $60 \%$ were well educated and the majority did not smoke cigarettes or drink alcohol. The average annual income was the earning of the individual being interviewed, and the almost 50\% unemployed persons included students, housewives and pensioners. Table 2 demonstrates that the study did not show a significant association between CAM usage and age, religion, education, gender, income, alcohol consumption, smoking status and employment.

\section{Prevalence}

The prevalence of CAM usage among the Indian community of Chatsworth for the period 2000/2001 was 38.5\% $(95 \% \mathrm{CI}=31.7 \%$ to $45.6 \%)$. In this group of CAM users the most troublesome conditions were diabetes mellitus (22.1\%), headaches $(22.1 \%)$, arthritis or joint pains $(18.2 \%)$, stress $(16.9 \%)$, skin disorders $(16.9 \%)$, backache (15.6\%), hypertension (15.6\%) and nasal disorders 
Table 2: The influence of the various demographic factors upon CAM usage

\begin{tabular}{|c|c|c|c|c|}
\hline Variable versus CAM use & Category I & Category 2 & Category 3 & P-value \\
\hline Age & $<45$ years & $>45$ years & & 0.209 \\
\hline Religion & Hinduism & Christianity & Islam & 0.995 \\
\hline Sex & Male & Female & & 0.365 \\
\hline Education level & $<$ Grade 9 & $>$ Grade 9 & & 0.195 \\
\hline Annual Income (Rands) & $<R 40000$ & $>\mathrm{R} 40000$ & & 0.666 \\
\hline Employment & Yes & No & & 0.198 \\
\hline Smoking status & Yes & No & & 0.399 \\
\hline Alcohol Consumption & Yes & No & & 0.515 \\
\hline
\end{tabular}

Table 3: Utilisation pattern of CAM

\begin{tabular}{ll}
\hline Type of CAM & Users (n) \\
\hline Herbal/natural medicines and/or vitamins & 37 \\
Spiritual healing & 33 \\
Commercial weight loss programme & 8 \\
Exercise and special diets not prescribed by your doctor & 7 \\
Aromatherapy & 6 \\
Ayurvedic medicine & 6 \\
Massage therapy excluding physiotherapy & 6 \\
Acupuncture & 3 \\
Homeopathy & 2 \\
Reflexology & 1 \\
\hline
\end{tabular}

(10.4\%). A total of $80.5 \%$ of CAM users visited a medical doctor in the previous 12 months. Thirty six CAM users $(46.8 \%)$ reported using CAM alone while thirty seven (50.7\%) used CAM together with allopathic medicines prescribed. (Four CAM users did not answer this question.) The two major types of CAM used were herbal/natural medicines including vitamins (48.1\%) and spiritual healing (42.9\%) (Table 3 ). The percentage of CAM users that used more than one type of CAM was $33.8 \%$. When asked to provide an estimate of the costs incurred in using CAM during the previous 12 months $96.1 \%$ responded as follows: $61.0 \%$ spent less than R200 (approximately US\$20), 19.5\% spent between R200 and R500 (approximately US\$20 and US\$50), 9.6\% spent between R500 and R1000 (approximately US\$50 and US\$100) and 9.1\% spent more than R1000.

\section{Communication with medical practitioners}

Of the 52 individuals that used CAM, excluding spiritual healing alone, $42.3 \%$ informed their doctors of CAM use. Two patients did not respond to this question and the remaining $53.8 \%$. did not inform their doctors that they were using CAM. Of the latter group, $89.3 \%$ responded with the following reasons: $53.6 \%$ thought it was unnecessary to inform their doctors $7.1 \%$ felt their doctor might become upset and $28.6 \%$ stated that their doctor did not enquire.

\section{Attitudes}

Greater than half (51.9\%) of the CAM users were either advised by somebody to try the alternate product/treatment modality or were influenced by advertisements in the local newspapers, books or magazines. For $37.6 \%$ of CAM users, modern medicine brought some improvement in their conditions but failed to cure the underlying problem. The concept that CAM was a natural and safe form of medical care was quoted by $23.4 \%$ of respondents whilst $15.6 \%$ chose CAM because modern medicine carried a risk of unwanted side effects or they had actually experienced such side effects. (Respondents could choose more than one reason for CAM use.) Of the respondents that used CAM, $14.3 \%$ expressed a preference for modern (allopathic) medicine, 51.9\% preferred CAM and 32.5\% would choose to use both modern medicine and CAM. Of those that did not use CAM, 120 patients(97.6\%) gave their preferred method as follows: $17.9 \%$ would choose CAM as a preferred method of healing, $11.4 \%$ would use both allopathic medicine and CAM and $68.3 \%$ would choose modern methods. The reasons for their choices are reported in table 4 . Beneficial effects were experienced by 
Table 4: Most common reasons for respondents' preference for allopathic medicine, CAM or both modalities to improve their health. Respondents could choose more than one alternative.

\begin{tabular}{|c|c|c|c|c|c|}
\hline \multirow{2}{*}{$\begin{array}{l}\text { Allopathic Medicine } \\
\text { Reasons }\end{array}$} & \multirow[b]{2}{*}{$\%$} & \multicolumn{2}{|l|}{ Both modalities } & \multicolumn{2}{|l|}{ CAM } \\
\hline & & Reasons & $\%$ & Reasons & $\%$ \\
\hline $\begin{array}{l}\text { No prior knowledge or experience of } \\
\text { CAM }\end{array}$ & 45 & CAM is a natural form of treatment & 61 & CAM is a natural form of treatment & 85 \\
\hline $\begin{array}{l}\text { More evidence that allopathic medicine } \\
\text { works }\end{array}$ & 36 & $\begin{array}{l}\text { More evidence that allopathic } \\
\text { medicine works }\end{array}$ & 44 & CAM safer than allopathic medicine & 40 \\
\hline $\begin{array}{l}\text { Allopathic medicine is more cost } \\
\text { effective than CAM }\end{array}$ & 19 & $\begin{array}{l}\text { Allopathic medicine more cost } \\
\text { effective }\end{array}$ & 39 & Evidence that CAM works & 21 \\
\hline
\end{tabular}

79.2\% of CAM users whilst $11.7 \%$ had no improvement in their illnesses. $9.1 \%$ of users were not sure if there were any beneficial effects at all.

\section{Discussion}

The percentage of people using CAM among the Indian community of Chatsworth $(38.5 \%)$ is comparable to that reported elsewhere in the world: $40 \%$ in the USA [5] and 48.5\% in Australia [3]. This community used CAM for illnesses that were generally chronic in nature. The American study [1] showed that one-third of the respondents used CAM for "non-serious medical conditions, health promotion or disease prevention". A study in Hong Kong showed that traditional Chinese medicine was considered suitable "as a supplement to Western medicine" [23]. Likewise, in the sample population for this study, half of the CAM users used CAM and allopathic medicine concurrently.

No demographic factor was found to be a significant predictor of CAM usage. These findings differ from the American and Australian studies, which both found several associations between demographic factors and CAM usage. Notably, college education and wealth were predictors common to both the US and Australian studies. Variation in the subject characteristics between our study and these previous studies may account for this difference. The proportion of subjects with tertiary education in the present study was $12 \%$ compared with $40 \%$ in both of the previous studies and $50 \%$ of subjects fell within the poorest wealth category compared with $30 \%$ in the other studies.

It was surprising to note that although CAM practitioners' services and products are extensively advertised in Chatsworth, 47 respondents had no prior knowledge or understanding of CAM. This was also the main reason given for preferring to use allopathic medicine (Table 4). It may be possible that such people, satisfied with allopathic medicine, do not attempt to learn about other treatment modalities. Although Ayurvedic medicine stems from India, only 6 respondents utilized this form of CAM. The reasons for this could form the basis of a future study. A possible explanation is that since allopathic medicine is the only form of medical care being taught at the local medical universities, people have had no choice but to accept this form of care. In Hong Kong, the Chinese community suffered a similar political fate under British rule wherein Traditional Chinese medicine prior to 1997 was not formally recognized by the then British government [23].

The proportion of Christians using spiritual healing was the same as those for the Hindus and Muslims. Strong cultural factors probably contribute to the reasons for the Indian community using prayer as a major healing form, although they may be of different faiths. Some of the herbal/natural medicines used included items such as spirulina, multivitamins and a particular brand of herbal products (Mother Nature ${ }^{\circledast}$ ), all of which are currently extensively advertised. It would therefore seem that advertising plays a major role in the use of herbal/natural medicines in the Chatsworth community.

The symptom-based nature of Western/allopathic medicine may be a drawback for patients who are interested in finding an explanation for their symptoms. People, who are unhappy with the root cause of the problem not being found, may try CAM as an alternative. In this study, the major reason given for CAM usage, cited by $38 \%$ of CAM users, was that though modern medicine brought some improvement in conditions it failed to cure the underlying problem. Modern medicine has used the curative approach to diseases, whereas traditional medicine has focused on healing illnesses and applying the systems approach. This approach considers the multitude of factors in the social and cultural environment of the patient that play a decisive role in the development and appearance of disease [24]. It is therefore a holistic perspective in therapy, whereby healing remedies have been chosen for their specific effects on a given condition, as well as for their symbolic and ritualistic value for a certain individual, treated in the context of his/her social and cultural environment. 
After spiritual healing had been excluded due to its lack of possible unwanted interaction with concurrent allopathic care, over half of the CAM users were still found not to inform their (allopathic) medical practitioners that they were using CAM. Findings in other studies have varied; in the Eisenberg studies only $39 \%$ and $40 \%$ of respondents using 'unconventional therapy' [5] and 39\% of CAM users in a Saskatchewan stroke population informed caregivers about their use of CAM [25]. In a study of CAM users with advanced-stage breast cancer in the USA, however, discussion with doctors was high for use of ingested CAM products (modalities most likely to interact negatively with conventional therapies) [26]. Our findings suggest patient-doctor communication needs improvement. Some respondents said that their doctors did not take a CAM medical history. Doctors may take it for granted that patients do not try CAM for their illnesses. Our recommendation is that medical doctors increase their attempts to ask their patients about their use of CAM. The inclusion of an outline of alternative therapies, as well as anthropological and sociological studies, in the curricula of our medical schools should be considered as a way to improve caregivers' understanding of their patients' health belief systems and usage of CAM.

\section{Competing interests}

None declared.

\section{Authors' contributions}

VS conceived of the study, participated in its design, coordinated the fieldwork, administered questionnaires, collated the data, participated in the data analysis and wrote the first draft of the manuscript. DR participated in the study design and data analysis and reviewed the manuscript. KH participated in the data analysis and interpretation and reviewed and edited the manuscript. All authors read and approved the final manuscript

\section{Additional material}

\section{Additional File 1}

Demographics of the 200 subjects interviewed. This is a table of subject characteristics in Word format.

Click here for file

[http://www.biomedcentral.com/content/supplementary/14726882-4-3-S1.doc]

\section{References}

I. Eisenberg DM, Kessler RC, Foster C, Norlock FE, Calkins DR, Delbanco TL: Unconventional Medicine in the United States -Prevalence, Costs, and Patterns of Use. N Engl J Med I993, 328:246-252.

2. Fisher P, Ward A: Medicine in Europe: Complementary medicine in Europe. BM] 1994, 309:107-III.

3. MacLennan AH, Wilson DH, Taylor AW: Prevalence and cost of alternative medicine in Australia. Lancet 1996, 347:569-573.
4. Kitai E, Vinker S, Sandiuk A, Hornik O, Zeltcer C, Gaver A: Use of complementary and alternative medicine among primary care patients. Fam Pract 1998, I 5:41 I-4I4.

5. Eisenberg DM, Davis RB, Ettner SL, Appel S, Wilkey S, Van Rompay $M$, Kessler RC: Trends in Alternative Medicine Use in the United States, 1990-1997: Results of a Follow-up National Survey. JAMA 1998, 280:1569-I575.

6. Barnes J, Abbot NC, Harkness EF, Ernst E: Articles on Complementary Medicine in the Mainstream Medical Literature: An Investigation of MEDLINE, 1966 Through 1996. Arch Intern Med 1999, 159:1721-1725.

7. Gundersen L: Faith and Healing. Ann Intern Med 2000, 132:169-172.

8. Gordon JS: Alternative medicine and the family physician. Am Fam Physician 1996, 15:2205-12, 22 I8-2220.

9. Moss CA: Five element acupuncture: treating body, mind, and spirit. Altern Ther Health Med. 1999, 5:52-61.

10. Schuster CS: Called to heal. Halfway House, Zebra Press; 1998:98-99.

II. Kaptchuk TJ, Eisenberg DM: The Persuasive Appeal of Alternative Medicine. Ann Intern Med 1998, I 29: 106I-1065.

12. Astin JA, Shapiro SL, Lee RA, Shapiro Jr DH: The construct of control in mind-body medicine: implications for healthcare. Altern Ther Health Med 1999, 5:42-47.

13. Husted C, Pham L, Hekking A, Niederman R: Improving quality of life for people with chronic conditions: the example of t'ai chi and multiple sclerosis. Altern Ther Health Med 1999, 5:70-74.

14. Rao JK, Mihaliak K, Kroenke K, Bradley J, Tierney WM, Weinberger M: Use of Complementary Therapies for Arthritis among Patients of Rheumatologists. Ann Intern Med 1999, 13 I:409-416.

15. Gaby AR: Natural treatments for osteoarthritis. Altern Med Rev 1999, 4:330-341.

16. Boon H, Stewart M, Kennard MA, Gray R, Sawka C, Brown JB, McWilliam C, Gavin A, Baron RA, Aaron D, Haines-Kamka T: Use of Complementary/Alternative Medicine by Breast Cancer Survivors in Ontario: Prevalence and Perceptions. J Clin Oncol 2000, I8:25|5-252I.

17. Crocetti E, Crotti N, Feltrin A, Ponton P, Geddes M, Buiatti E: The use of complementary therapies by breast cancer patients attending conventional treatment. Eur J Cancer 1998, 34:324-328.

18. Blanc PD, Kuschner WG, Katz PP, Yelin EH: Reanalysis of Blanc PD et al, "Use of herbal products, coffee or black tea, and over-the-counter medications as self treatments among adults with asthma". J Allergy Clin Immunol 2000, 106:196.

19. Rawsthorne P, Shanahan F, Cronin NC, Anton PA, Lofberg R, Bohman L, Bernstein CN: An international survey of the use and attitudes regarding alternative medicine by patients with inflammatory bowel disease. Am J Gastroenterol 1999, 94:1298-1303.

20. Launso L, Brendstrup E, Arnberg S: An exploratory study of reflexological treatment for headache. Altern Ther Health Med. 1999, 5:57-65.

21. Buckle J: Use of aromatherapy as a complementary treatment for chronic pain. Altern Ther Health Med. 1999, 5:42-5I.

22. Singh BB, Berman BM, Hadhazy VA, Creamer P: A pilot study of cognitive behavioral therapy in fibromyalgia. Altern Ther Health Med. 1998, 4:67-70

23. Lam TP: Strengths and weaknesses of traditional Chinese medicine and Western medicine in the eyes of some Hong Kong Chinese. J Epidemiol Community Health 200I, 55:762-765.

24. Hedberg I, Staugard F: Traditional medicinal plants. Stockholm, Ipeleng publishers; 1989.

25. Blackmer J, Jefromova $L$ : The use of alternative therapies in the Saskatchewan stroke rehabilitation population. BMC Complementary and Alternative Medicine 2002, 2(7):

26. Shen J, Andersen R, Albert P, Wenger N, Glaspy J, Cole M, Shekelle $P$ : Use of complementary/alternative therapies by women with advanced-stage breast cancer. BMC Complementary and Alternative Medicine 2002, 2(8):

\section{Pre-publication history}

The pre-publication history for this paper can be accessed here: 
http://www.biomedcentral.com/1472-6882/4/3/prepub

Publish with Bio Med Central and every scientist can read your work free of charge

"BioMed Central will be the most significant development for disseminating the results of biomedical research in our lifetime. " Sir Paul Nurse, Cancer Research UK

Your research papers will be:

- available free of charge to the entire biomedical community

- peer reviewed and published immediately upon acceptance

- cited in PubMed and archived on PubMed Central

- yours - you keep the copyright 